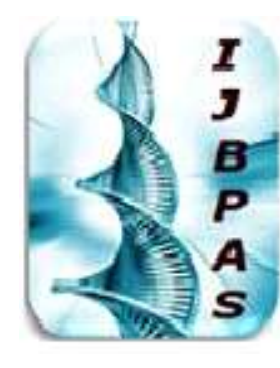

International Journal of Hiology, Pharmacy and Allied Seiences (IJBPAS) 'A Bridge Betuen Caboratory and Qnendo' Www.jibpas.com

\title{
RECENT APPROCHES OF IMPURITY PROFILING IN PHARMACEUTICAL ANALYSIS: A SYSTEMATIC REVIEW \\ KADAM $S^{*}$, VIDHATE P, DHOBALE S, JADHAV S AND GAIKWAD D
}

Vishal Junnar Seva Mandal's Vishal Institute of Pharmaceutical Education and Research, Ale, Tal. Junnar, Dist. Pune, M.S., India

*Corresponding Author: E Mail: vidhatepooja7@gmail.com

Received 27 ${ }^{\text {th }}$ April 2021; Revised $25^{\text {th }}$ June 2021; Accepted $1^{\text {st }}$ Aug. 2021; Available online $1^{\text {st }}$ Oct. 2021

https://doi.org/10.31032/IJBPAS/2021/10.10.1036

\begin{abstract}
Impurity is something this is impure or makes something else impure. An impure substance can be defined as follows: a substance of interest combined or impregnated with an extraneous or normally inferior substance, from the perspective of its utilization, the drug substance is compromised in terms of purity even supposing it includes any other cloth with advanced pharmacological or toxicological houses. The impurity can be advanced both throughout method, or upon ageing of both API's and formulated API's in drug treatments. The presence of those unwanted chemical compounds, even in small amount, may additionally influence the efficacy and protection of the pharmaceutical merchandise. The impurities are not necessarily usually inferior. Highly state-of-the-art instrumentation, consisting of mass spectra meters attached to a Gas Chromatography or HPLC, are inevitable equipment in the identification of stripling additives (pills, impurities, degradation products, metabolites) in various matrices. Present article well-known shows extraordinary impurities discovered inside the API's, strategies for identifying them and the feasible measures to deal with the interferences due to them in pharmaceutical analysis. Thus, in this review an attempt has been made to study the impurity profiling of pharmaceuticals.
\end{abstract}

Keywords: Impurity Profiling, API, Gas Chromatography, HPLC 


\section{INTRODUCTION}

The purity of a drug product is in turn decided on the premise of the share of the labelled quantity of API determined in it via a appropriate analytical technique. The presence of a few impurities might not deleteriously impact on drug nice if they have healing efficacy that is much like or more than the drug substance itself. Nevertheless, drug substances can be considered as compromised with appreciate to purity even though it carries an impurity with advanced pharmacological or toxicological assets [1].

Consequently, with the intention to make sure that an accurate amount of the drug substance is being administered to the affected person, drug substance purity need to be assessed independently from these unwanted extraneous materials (e.G., inert, toxic, or pharmacologically Superior impurities). Impurity profiling is the not unusual call of a group of analytical activities, the intention of that's the detection, identity/structure elucidation and quantitative determination of organic and inorganic impurities as well as residual solvents in bulk pills and pharmaceutical formulations. The distinct pharmacopoeias, such as the British Pharmacopoeia (BP) and the United States Pharmacopoeia (USP) are slowly incorporating limits to allowable stages of impurities present in the API's or formulations [2].

Various regulatory government like ICH, USFDA, Canadian Drug and Health Agency are emphasizing at the purity necessities and the identification of impurities in Active Pharmaceutical Ingredients (API's). Qualification of the impurities is the procedure of acquiring and evaluating statistics that establishes organic protection of an person impurity therefore, revealing the need and scope of impurity profiling of medication in pharmaceutical studies. International Conference on Harmonization (ICH) has published hints on impurities in new drug substances, products and residual solvents [3].

There is a great substantial demand for the impurity- reference standards along with the API reference requirements from each regulatory government and pharmaceutical agencies. The estimation of impurity profiles in drug materials and associated substances has end up one of the maximum crucial fields of pastime in modern pharmaceutical evaluation. In popular, all impurities found in extra of zero. $1 \%$ need to be identified, for the subsequent reasons 1-three: 
(1) On the idea of the information thus acquired artificial natural chemists are often able to keep away from the formation of the impurity in question or to develop a purification method to decrease its quantity to a tolerable degree.

(2) Following the structural identification of an unavoidable impurity, it is able to be synthesized to offer a sufficient quantity for:

a. Final evidence of its shape;

b. Its use as an "impurity wellknown";

c. Its use in toxicological studies.

ICH Q3A covers drug substances and Q3B covers drug products. These recommendations outline what investigations and documentation ought to be made in investigating impurities and degradation merchandise visible in stability research at endorsed storage conditions. In popular, according to ICH recommendations on impurities in new drug merchandise, identity of impurities under the zero.1\% stage is not considered to be important except the capability impurities are anticipated to be unusually effective or poisonous. In all instances, impurities should be qualified. If records are not to be had to qualify the proposed specification level of an impurity, studies to obtain such statistics can be wanted (whilst the standard qualification threshold limits given below are surpassed) [4-7]. According to $\mathrm{ICH}$, the maximum daily dose qualification threshold is considered as follows:

$\leq 2 \mathrm{~g}$ /day $0.1 \%$ or $1 \mathrm{mg}$ in keeping with day consumption (whichever is decrease) $\geq 2 \mathrm{~g} /$ day zero.05\% Sources/Types of impurity in Medicine: The pharmaceutical practise have to be unfastened from poisonous and other impurities. Pharmacopoeia prescribes limits for dangerous compound found in materials.

\section{Impurities generally discovered in}

\section{Medicinal arrangements:}

- Activity miserable impurities.

- Due to coloring or flavoring substances, e.g., Sodium Salicylate.

- Humidity.

- Decrease shelf lifestyles.

- Physical and chemical homes.

- Impurities because of which substances turn out to be incompatible. 


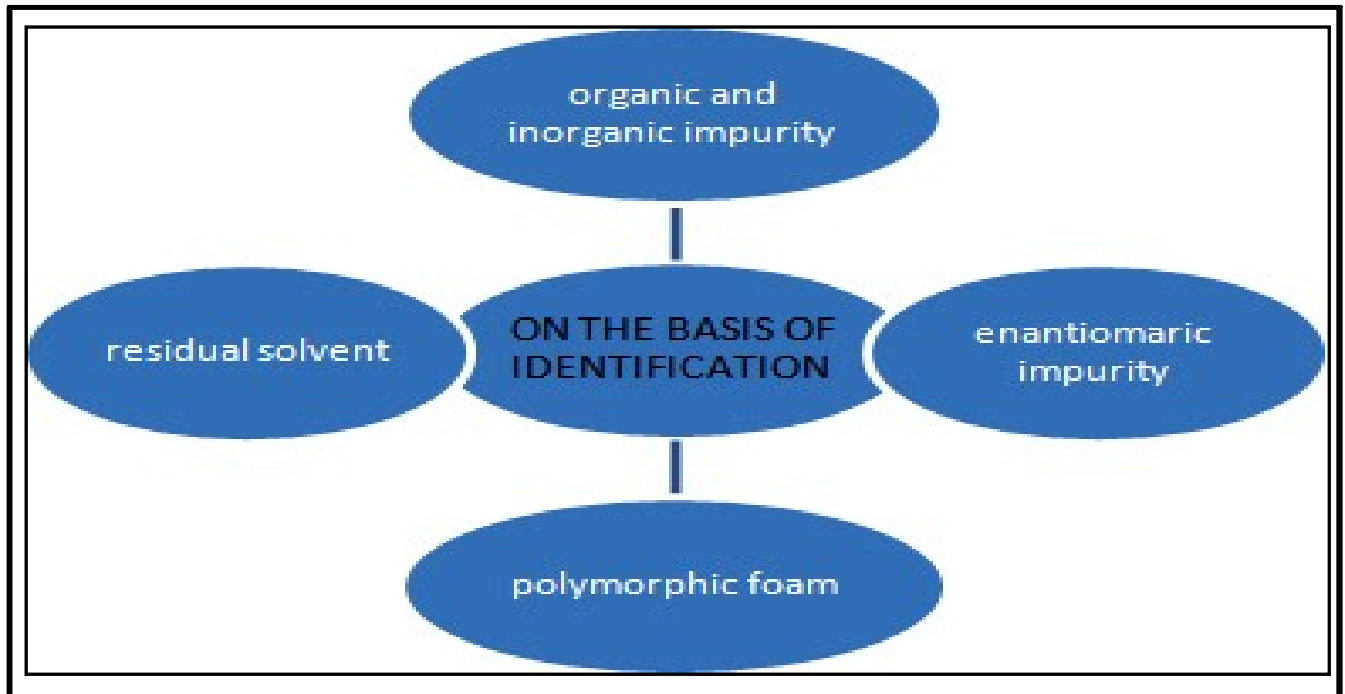

Figure 1: Classification of Impurity

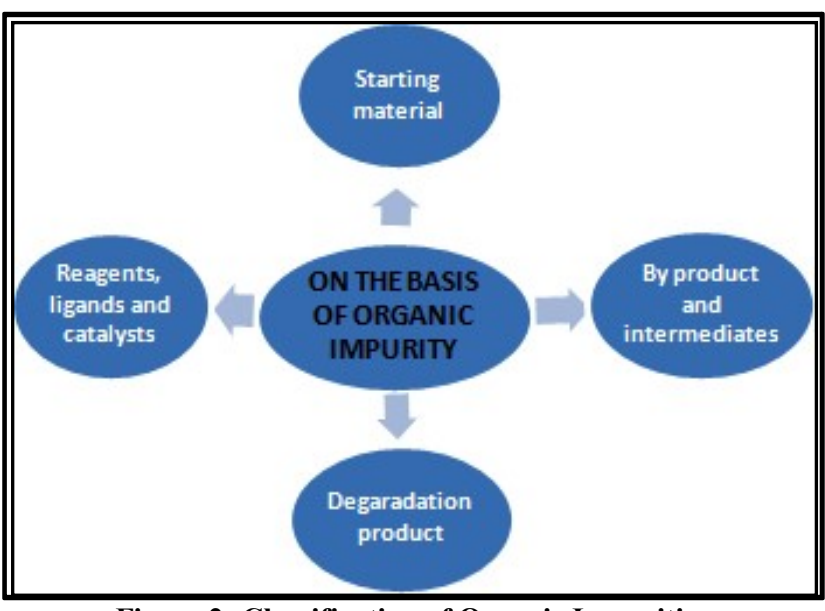

Figure 2: Classification of Organic Impurities

\section{IMPURITIES IN CASE OF}

\section{PHARMACEUTICALS $[8,9]$}

1. Impurities arising during storage: A range of impurities can originate for the duration of garage or cargo of drug products. It is crucial to perform stability research to predict, compare, and make sure drug product safety.

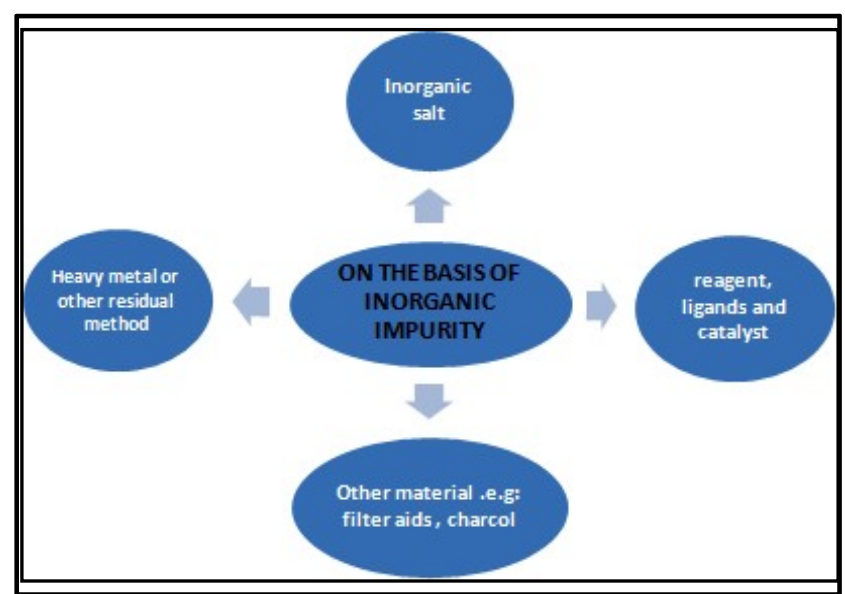

Figure 3: Classification of Inorganic Impurities

2. Method Related Impurity: A regarded impurity, 1- $(2$, 6dichlorophenyl) indolin-2-one is formed within the manufacturing of a parenteral dosage form of diclofenac sodium, if it's miles terminally sterilized by way of autoclave. The conditions of the autoclave method 
(i.E., $123+2^{\circ} \mathrm{C}$ ) implement the intramolecular cyclic reaction of diclofenac sodium forming an indolinone by-product and sodium hydroxide. The formation of this impurity has been determined to depend on preliminary $\mathrm{pH}$ of the method.

\section{Mutual interplay among ingredients:}

Most vitamins are very labile and on getting older they create a problem of instability in extraordinary dosage bureaucracy, especially in liquid dosage bureaucracy. Degradation of vitamins does no longer deliver poisonous impurities; but, potency of energetic elements drops underneath Pharmacopoeial specs. Because of mutual interplay, the presence of nicotinamide in a method containing four nutrients (nicotinamide, pyridoxine, riboflavin, and thiamine) can reason the degradation of thiamine to a sub- standard level inside a 365 days shelf lifestyles of vitamin Bcomplicated injections. The marketed samples of nutrition B-complicated injections had been found to have a $\mathrm{pH}$ variety of $2.8-4.0$. A custom-made formula with simple distilled-water and a regular formulated car along with disodium edetate and benzyl alcohol were investigated, and comparable mutual interactions inflicting degradation have been observed.

\section{Functional group-related Typical}

Degradation: Ester hydrolysis can be defined with a few tablets viz aspirin, benzocaine, cefotaxime, ethyl paraben and cefpodoxime proxetil. Hydrolysis is the not unusual phenomenon for ester kind of drugs, in particular in liquid dosage bureaucracy viz benzylpenicillin, oxazepam and lincomycin. Oxidative degradation of drugs like hydrocortisone, methotrexate, hydroxyl institution at once bonded to an fragrant ring (viz phenol derivatives consisting of catecholamines and morphine), conjugated dienes (viz nutrition $\mathrm{A}$ and unsaturated free fatty acids), heterocyclic fragrant jewelry, nitroso and nitrite derivatives, and aldehydes (specially flavorings) are all liable to oxidative degradation. In mazipredone, the hydrolytic and oxidative degredation pathway in 0.1 mol L-1 hydrochloric acid and sodium hydroxide at $80^{\circ} \mathrm{C}$ had been studied. 
Table 1: Classification of Solvents On The Basis Of Their Limit In Parts Per Million (ppm)

\begin{tabular}{|c|c|c|}
\hline CATEGORY & NAME OF THE SOLVENT/LIMIT & UNIT/SPECIFICATION \\
\hline Class 1 & $\begin{array}{c}\text { Benzene (2ppm), carbon tetra chloride (4ppm), methyl } \\
\text { chloride (600ppm), methanol (3000ppm), pyridine } \\
(200 p p m), \text { ethanol }\end{array}$ & More than this should be avoided \\
\hline Class 2 & N, N-dimethylformamide (800ppm), Acetonitrile (410) & More than this should be avoided \\
\hline Class 3 & Acetic acid, ethanol, acetone (50mg) & $\begin{array}{c}\text { Have permitted daily exposure of 50mg or } \\
\text { less per day as per ICH guidelines }\end{array}$ \\
\hline
\end{tabular}

Table 2: Classification of Metals On The Basis of Their Safety Concern

\begin{tabular}{|c|c|}
\hline Category & Example \\
\hline $\begin{array}{c}\text { Class -1 (metal of significant safety } \\
\text { concern) }\end{array}$ & $\begin{array}{c}\text { Ir (Iridium), pt (platinum), Rh (rubidium), Mo (molybdenum), V (vanadium), Cr } \\
\text { (chromium), Ni (nickel). }\end{array}$ \\
\hline $\begin{array}{c}\text { Class -2 (Metal with low safety } \\
\text { concern) }\end{array}$ & Cu (copper), Mn (manganese) \\
\hline $\begin{array}{c}\text { Class -3 (Metal with minimal safety } \\
\text { concern) }\end{array}$ & Fe (iron) and Zn (zinc). \\
\hline
\end{tabular}

Table 3: Classification of Q-Guideline On The Basis Of Impurity

\begin{tabular}{|c|c|c|}
\hline Section & Impurities & Sub-section \\
\hline Q3A(R2) & Impurities in new drug substance & Q3A(R) \\
\hline Q3B(R2) & Impurities in new drug products & Q3B(R) \\
\hline & Impurities: guidelines for residual solvents & Q3C \\
Q3C(R4) & Impurities: guidelines for residual solvents (Maintenance) & Q3C \\
& PDE for tetrahydrofuran [in Q3c(R3)] & \\
& PDE for N-methylpyrrolidone [in Q3c(R3)] & Q3C \\
\hline
\end{tabular}

Table 4: Thresholds for Reporting Impurities

\begin{tabular}{|c|c|c|c|}
\hline Maximum dose & Reporting threshold & Identification threshold & Qualification threshold \\
\hline Less or equal to $2 \mathrm{gm} / \mathrm{day}$ & $0.05 \%$ & $\begin{array}{c}0.1 \% \text { or } 1 \mathrm{mg} / \mathrm{day} \text { (Which is } \\
\text { lower) }\end{array}$ & $\begin{array}{c}0.15 \% \text { or } 1 \mathrm{mg} / \mathrm{day} \text { (Which is } \\
\text { lower) }\end{array}$ \\
\hline$>2 \mathrm{gm} / \mathrm{day}$ & $0.03 \%$ & $0.05 \%$ & $0.05 \%$ \\
\hline
\end{tabular}

Table 5: Threshold For Reporting Degaradation Products In New Drugs Products

\begin{tabular}{|c|c|}
\hline Maximum daily dose & Threshold \\
\hline 1gm & $0.1 \%$ \\
\hline$>1$ gm & $\mathbf{0 . 0 5 \%}$ \\
\hline
\end{tabular}

\section{Selective Analytical Methodologies:}

The impurities can be recognized predominantly by means of following strategies [13-16];

- Reference wellknown method

- Spectroscopic approach

- Separation method

- Isolation technique

- Characterization method
Reference trendy method: The key objective of that is to offer clarity to the overall existence cycle qualification and governance of reference widespread utilized in improvement and control of latest drug. Reference standards serve as the premise of assessment of both method and product overall performance and are the benchmarks for assessment of drug safety for affected person intake. These widespread are needed, 
now not handiest for the energetic substances in dosage forms however also for impurities, degradation merchandise, starting materials, system intermediates, and excipient.

\section{Spectroscopic techniques [17]:}

The following spectroscopic techniques can be used;
A. Ultraviolet (UV)
B. Infrared (IR)
C. Nuclear magnetic resonance (NMR)

D. Mass spectrometry (MS)

Separation methods: The following separation strategies may be used [18-20]:

a) Thin-layer chromatography (TLC)

b) Gas chromatography (GC)

c) High-stress liquid chromatography (HPLC)

d) Capillary electrophoresis (CE)

e) Supercritical fluid chromatography (SFC)

Table 6: Drug and Their Impurities Method of Detection [21-23]

\begin{tabular}{|c|c|c|c|}
\hline Sr. No. & Drugs & Impurities & Method \\
\hline 1. & Amphotericin B & Teteaenes & UV spectroscopy \\
\hline 2. & Atropine sulphate & Apo atropine & UV spectroscopy \\
\hline 3. & Cloxacillin & N, N -dimethyl & Gas chromatography \\
\hline 4. & Dextrose & 5- hydroxy methyl furfural & UV spectroscopy \\
\hline 5. & $\begin{array}{l}\text { Doxorubicin } \\
\text { hydrochloride }\end{array}$ & Acetone and Ethanol & Gas chromatography \\
\hline 6. & $\begin{array}{c}\text { Ethambutol } \\
\text { hydrochloride }\end{array}$ & 2 -amino butanol & TLC \\
\hline 7. & Fluorescence sodium & Dimethyl formamide & Gas chromatography \\
\hline 8. & Framicetinsulphate & Neamine & TLC \\
\hline 9. & Morphin & 6- mono acetylmorphin & HPLC \\
\hline 10. & 10-hydroxymorphin & 10- oxomorphin & HPLC \\
\hline 11. & Mercaptopurin & $\begin{array}{l}\text { Hypoxanthin ,2,5-bis*(N' cyano-N"'- } \\
\text { methyl)guinidinoethylthiomethyl]-4-methylimidazol }\end{array}$ & UV spectroscopy \\
\hline 12. & Norgestrei & 3,17a-diethyl-13 ethyl-3,5-gonadiene-17-ol spectroscopy & TLC, HPLC and UV \\
\hline 13. & Cimitidine & 1,8-bis*(N' cyano-N''-methyl)guinidino]-3,6-dithiaoctane & HPLC \\
\hline 14. & Celecoxib & $\begin{array}{c}\text { [5-(4-methylphenyl)-3-trifluromethyl-1H-pyrazole],4-[5-(2'- } \\
\text { methylphenyl)-3-(trifluromethyl-1H-pyrazole-1-yl]- } \\
\text { benzenesulphonamide,and4-[4-(4'-methyl phenyl)-3- } \\
\text { (trifluromethyl)-1-Hpyrazole-1-yl]-benzenesulphonamide }\end{array}$ & $\begin{array}{l}\text { HPLC, LC, LC-MS- } \\
\text { MS }\end{array}$ \\
\hline 15. & Ethynodioldiacetate & $\begin{array}{c}17 \text { a-ethinylestr-4-ene-3a,17-diol-3-acetate-17-(3'-acetoxy- } \\
\text { 2'- butenoate)17 a-ethinylestr-4-ene-3a,17-diol-3-acetate- } \\
\text { 17-(3- } \\
\text { oxo-butanoate) }\end{array}$ & HPLC \\
\hline 16. & Methamphetamine & $\begin{array}{c}\text { 1,2-dimethyl-3-phnylaziride,ephedrine,methylephedrine, } \mathrm{N}- \\
\text { formylmethamphetamine, } \mathrm{N}-\text { acetylmethamphitamine,, } \mathrm{N}- \\
\text { formylphedrine, } \mathrm{N} \text { - } \\
\text { acetylephedrine, } \mathrm{N}, \text { Oacetylephedrine,methametamine } \\
\text { dimmer }\end{array}$ & HPLC \\
\hline 17. & Repaglinide & $\begin{array}{l}\text { 4-carboxymethyl-2-ethoxybenzoic acid,4- } \\
\text { cyclohexylaminocarbamoylmethyl-2ethoxy-benzoic acid,1- } \\
\text { cyclohexyl-3-[3-methyl-1-2-(piperidine-1-ylphenyl)-butyl]- } \\
\text { urea,1,3-dicyclohexyl urea }\end{array}$ & GC \\
\hline 18. & Morphine & 6-monoacetylmorphine & HPLC \\
\hline 19. & Morphine sulphate & 5-(hydroxymethyl)2-furfural & HPLC \\
\hline 20. & 10-hydroxymorphine & 10-oxomorphine & HPLC \\
\hline
\end{tabular}


Goals of Impurity Investigations [24, 25]:

\begin{tabular}{|l|l|}
\hline Process-related impurities & Degradation-related impurities \\
\hline Identify significant impurities & $\begin{array}{l}\text { Identify potential degradation product through stress } \\
\text { testing and } \\
\text { actual degradation products through stability studies. }\end{array}$ \\
\hline $\begin{array}{l}\text { Determine origin of impurities and method for } \\
\text { elimination or } \\
\text { Reduction }\end{array}$ & $\begin{array}{l}\text { Understand degradation pathway and methods to } \\
\text { minimize } \\
\text { degradation. }\end{array}$ \\
\hline $\begin{array}{l}\text { Establish a control system } \\
\text { for impurities involving: }\end{array}$ & $\begin{array}{l}\text { Establish a control system } \\
\text { for impurities involving: } \\
\text { 1) Processing/manufacturing conditions } \\
\text { 2) Suitable analytical methods/ specifications }\end{array}$ \\
& $\begin{array}{l}\text { 1) Processing/manufacturing conditions } \\
\text { 2)Suitable analytical methods/specifications } \\
\text { 3)Long term storage conditions including packaging } \\
\end{array}$ \\
\hline
\end{tabular}

\section{CONCLUSION}

This overview presents a angle on impurities in drug substance and drug product. Impurity profile of prescribed drugs is receiving an growing significance and drug protection receives increasingly interest from the public and from the media. This article provides the treasured statistics approximately the impurities kinds and its class, diverse techniques of isolation and characterization, analytical strategies for the willpower, qualification of impurities and crucial factors to be taken into consideration at the same time as practice of the bulk pills. Now an afternoon, it's miles obligatory requirement in numerous pharmacopoeias to understand the impurities present in API's. Isolation and characterization of impurities is required for obtaining and evaluating facts that establishes biological protection which wellknown shows the need and scope of impurity profiling of medication in pharmaceutical research.

\section{REFERENCES}

[1] Ahuja S. impurities evaluation of pharmaceutical, Dekker, New York, 1998.

[2] Gorog S., identification and determination of impurities in drugs, Elsevier, Amsterdam,2000

[3] Ahuja S. Alsante K., Handbook of isolation and characterization of impurities in pharmaceuticals, academic, san Diego, CA, 2003

[4] International Conference on Harmonization (2000) Draft Revised Guidance on Impurities In New Drug Substances. Federal Register Q3A(R) 65 (140): 45085.

[5] International Conference on Harmonization (2000) Draft Revised Guidance on Impurities In New Drug Products. Federal Register Q3B(R) 65 (139): 44791. 
[6] International Conference on Harmonization (1997) Impurities, Q3CGuidelines for Residual Solvents, Q3C. Federal Register 62(247): 67377.

[7] International Conference on Harmonization (1999) Specifications, Q6A: Test Procedures and Acceptance Criterial for New Drug Substances and New Drug Products. Chemical substances 65 (146):67488.

[8] Parimoo P., et al; 'A Text Book of Pharmaceutical Analysis', CBS publishers and distributors, New Delhi, 1998, 14.

[9] Parimoo P., et al; 'A Text Book of Pharmaceutical Analysis', CBS publishers and distributors, New Delhi, 1998, 20, 21.

[10]Alsante $\mathrm{K} \mathrm{M}$, Boutres $\mathrm{P}$, et al; 'Pharmaceutical Impurity Identification: A Case Study Using a Multidisciplinary Approach', Journal of Pharmaceutical Sciences (2004) 93 (9): 2296.

[11]I.P.1996 (Indian Pharmacopoeia-1996) Govt. of India, Ministry of Health and Family Welfare, Vol.-I, 1996 Edition, published by the Controller of Publication, Delhi.

[12] Sanjay B. Bari, Bharati R. Kadam, Yogini S. Jaiswal, Atul A. Shirkhedkar Impurity profile: Significance in Active Pharmaceutical Ingredient Eurasian
Journal of Analytical Chemistry Volume 2, Number 1, 2007

[13]Ahuja S and Scypinski S (2001) Handbook of Modern Pharmaceutical Analysis, Academic Press, NY, 298.

[14]Ahuja S, (1997) Chiral Separations by Chromatography, Oxford University Press, NY, 365.

[15] Ahuja S (1992) Chromatography of Pharmaceuticals: Natural, Synthetic and Recombinant Products. ACS Symposium Series \#512, Ame Chem Soc, Washington, DC, 14.

[16] Ahuja S (1992) Trace and Ultra trace Analysis by HPLC, Willey, New York, 84

[17] Ahuja S, Trace and Ultra trace Analysis by HPLC, Wiley, New York,1992

[18]Ahuja S, Chromatography and Separation Science, Academic, San Diego, CA, 2003.

[19] Ahuja S., Scypinsky S., Handbook of Modern Pharmaceutical Analysis, Academic, New York, NY, 2001.

[20] Ahuja S., Dong M., Handbook of Pharmaceutical Analysis by HPLC, Academic, San Diego, CA, 2005.

[21] Peter J S, Ahmed A and Yan W (2006) An HPLC chromatographic reactor approach for investigating the hydrolytic stability of a pharmaceutical compound. 
J Pharm Biomed Anal 41: 883.

[22] Radhakrishna T, Satynarayana J and Satynarayana A (2002) Determination of Loratidine and its Related Impurities by HPLC. Indian Drugs 39 (6): 342.

[23] Radhakrishna T, Satynarayana $J$ and Satynarayana A (2002) HPLC method for the Degradation of Celecoxib and its Related Impurities. Indian Drugs 40(3): 166.

[24]Zawilla N H, Li B, Hoogmartens J and Adams E (2006) Improved RP-LC method combined with pulsed electrochemical detection for the analysis of amikacin. J Pharm Biomed Anal 42: 114.

[25]Fiori J, Bragieri M, Zanotti M C, Liverani A, Borzatta V, Mancini F, Cavrini V and Andrisano V (2005) LCTMS for the identification of impurities in d-allethrine samples. J Chromatogr A 1099:149. 